\title{
Increased cancer risk after myocardial infarction: fact or fiction? A systemic review and meta-analysis
}

This article was published in the following Dove Medical Press journal: Cancer Management and Research

\author{
$\mathrm{Na} \mathrm{Li}{ }^{1, *}$ \\ Zhigang Huangl,* \\ Yanda Zhang ${ }^{1, *}$ \\ Haitao Sun ${ }^{2}$ \\ Jiamei Wang' \\ Jian Zhao'
}

'Department of Cardiology, Changzheng Hospital, Second Military Medical University, Shanghai 200003, China; ${ }^{2}$ Department of Oncology, Changzheng Hospital, Second Military Medical University, Shanghai 200003, China

*These authors contributed equally to this work
Correspondence: Jian Zhao Department of Cardiology, Changzheng Hospital, Second Military Medical University, 415 Fengyang Road, Huangpu District, Shanghai 200003, China

Tel +8621885261

$\mathrm{Fax}+862163520020$

Email drzhaojiansmmu@163.com
Objective: Accumulating evidences showed some positive relations between myocardial infarction (MI) and new onset cancer. We aim to investigate whether MI is associated with an increased risk of incident cancer.

Methods: A comprehensive literature list was identified from MEDLINE, Embase, and Web of Science databases from inception until October 2018. The main inclusion criteria included observational studies investigating the association between MI and new onset cancer. Stata 12.0 software was used for meta-analysis.

Results: Of 862 potentially relevant studies, five cohort studies met all inclusion criteria. The pooled cancer incidence rate was $9.5 \%(95 \% \mathrm{CI}=8.3-10.7 \%)$. Pooled analysis of OR showed that the increased overall cancer risk in MI patients in comparison with controls had no statistical significance $(\mathrm{OR}=1.08 ; 95 \% \mathrm{CI}=0.97-1.19, P=0.153)$. Subgroup analysis by gender demonstrated that the overall cancer risk was only significantly increased in female $(\mathrm{OR}=1.10 ; 95 \%$ $\mathrm{CI}=1.01-1.20, P=0.025)$, but not in male patients $(\mathrm{OR}=1.04 ; 95 \% \mathrm{CI}=0.99-1.10, P=0.124)$. In terms of cancer type, the increased cancer risk was only significant for lung cancer (male $\mathrm{OR}=1.12$; $95 \% \mathrm{CI}=1.05-1.19, P<0.01$; and female $\mathrm{OR}=1.51 ; 95 \% \mathrm{CI}=1.15-1.99, P<0.01)$, but not for prostate $(\mathrm{OR}=0.96 ; 95 \% \mathrm{CI}=0.85-1.09, P=0.546)$ or breast cancer $(\mathrm{OR}=0.94 ; 95 \%$ $\mathrm{CI}=0.86-1.04, P=0.222)$. In addition, the increased cancer risk was only significant in the first 6 months $(\mathrm{OR}=1.93 ; 95 \% \mathrm{CI}=1.42-2.63, P<0.01)$ but not in 6 months-1-year $(\mathrm{OR}=1.03 ; 95 \%$ $\mathrm{CI}=0.92-1.15, P=0.627)$ or $>1$-year $(\mathrm{OR}=0.98 ; 95 \% \mathrm{CI}=0.93-1.04, P=0.585)$ follow-up after MI. Conclusion: From available evidence, the increased overall cancer risk after MI was only significant in female but not in male patients. Besides, the increased cancer risk could be driven by increased short-term cancer incidence after MI and certain cancer types such as lung cancer. Keywords: myocardial infarction, incident cancer, meta-analysis

\section{Introduction}

Myocardial infarction (MI) and cancer are two leading causes of morbidity and mortality worldwide. With the development of pharmacotherapy and timely cardiac revascularization, in past decades, the prognosis of MI has been fundamentally improved with higher survival rate. ${ }^{1}$ Recently, some studies have suggested cardiovascular diseases including MI and cancer share a number of risk factors and possess various similarities. $^{2,3}$ Inflammation, oxidative stress, obesity, and smoking are all contributors to the occurrence of MI and cancer. ${ }^{4-7}$ Some observational studies also found noncardiac causes (mainly malignancies and chronic diseases) are responsible for the majority of later deaths in MI patients treated with percutaneous coronary intervention. ${ }^{8,9}$ Thus, it 
is plausible to assume that patients with MI history are more likely to develop incident cancer.

Meanwhile, in past years, several clinical and epidemiological studies have been done in this field and showed some positive associations between MI and new onset cancer. ${ }^{10,11}$ However, the results were inconsistent or even conflicting. ${ }^{12,13}$ In view of the high disease burden of MI and cancer, it is necessary to confirm whether MI is a new risk factor for incident cancer. Therefore, we conducted a systematic review and meta-analysis in accordance with the PRISMA guidelines and our predesigned protocol to clarify the association between MI and incident cancer.

\section{Methods}

\section{Literature search}

Two investigators independently reviewed published studies in MEDLINE, Embase, and Web of Science databases from their inception to October 2018 by using the following index terms: myocardial infarction OR myocardial infarct OR heart attack OR myocardial injury AND cancer incidence OR incident cancer OR new onset cancer OR cancer risk OR carcinogenesis OR tumorigenesis OR oncogenesis. A manual search for additional studies using references of selected retrieved articles was also performed to identify other possible studies. We also conducted searches of conference proceedings from major cardiology and oncology meetings for additional abstracts on the topic. No limitation on language was applied. The last date of the search was October 23, 2018.

\section{Inclusion and exclusion criteria}

The inclusion criteria were as follows: 1) observational studies; 2) studies investigating myocardial infarction and cancer incidence; 3) myocardial infarction was clearly diagnosed and new onset cancer occurred after myocardial infarction; and 4) cancer incidence rate or RR, OR, HR or standardized incidence ratio (SIR) with $95 \%$ CI were provided.

Exclusion criteria: 1) duplicate publications; 2) publication types were not observational studies; 3 ) cancer incidence was before or concurrent with MI; and 4) studies were also excluded if relevant data were not reported or extractable.

\section{Quality assessment}

The quality of each study was assessed by two reviewers. Newcastle Ottawa scale (NOS) generating stars for selection (S), comparability (C) and outcome (O) for cohort and case-control studies were used to evaluate studies' quality and risk of bias. ${ }^{14}$ Studies with seven stars or more were assumed to be of high quality, between five and seven stars to be of moderate quality, and less than five stars to be of low quality.

\section{Data extraction}

Data extraction was performed independently using a predefined data extract form by two reviewers. The data extracted from each study included the following information: first author's name, publication year, study design, country, number of patients and controls, gender, cancer incidence, and effect estimates (OR, RR, HR, or SIR) with 95\% CI and factors adjusted in the multivariate analysis. If both crude and adjusted values were provided, we only extracted the adjusted ones. Disagreement was resolved by discussion among all investigators.

\section{Statistical analysis}

All analysis was performed using Stata 12.0 software (StataCorp, College Station, TX). The risk of cancer incidence after MI was assessed by ORs and the corresponding 95\% CIs. An OR $<1$ reflects a favorable outcome in MI group compared with controls and indicates lower cancer incidence rate, and vice versa. A two-sided $P$-value of 0.05 was considered statistically significant for all included analysis. Generic inverse variance (DerSimonian and Laird) method was employed to combine adjusted point estimates and standard errors from each study. ${ }^{15}$ If effect estimates were presented for a number of categories of exposure, we would combine the corresponding estimates using the method proposed by Hamling et al. ${ }^{16}$

$Q$ test and $\mathrm{I}^{2}$ statistic were used to ascertain the betweenstudy heterogeneity. A value of $\mathrm{I}^{2}$ of $0 \%-25 \%, 25 \%-50 \%$, $50 \%-75 \%$, and $>75 \%$ embodied insignificant, low, moderate, and high heterogeneity, respectively. ${ }^{17}$ In light of the high likelihood of between-study variance, we used a randomeffect model rather than a fixed-effect model. Subgroup analysis would be done based on gender, cancer type, and follow-up time.

Publication bias was assessed by Begg's test and Egger's test. ${ }^{18,19} P<0.05$ indicated bias, and $P>0.05$ indicated no publication bias.

\section{Results}

Search results and characteristics of studies included

Of 862 potentially relevant articles, 846 articles were excluded due to duplication or the title and abstract not meeting inclusion criteria. Subsequently, 11 articles were excluded because of data duplication or lack of the outcomes 
of interest. Finally, five cohort studies met all inclusion criteria. ${ }^{10-13,20}$ One of them was a single-arm cohort study regarding $\mathrm{MI}$ and only provided cancer incidence rate. The rest of the studies supplied overall or subgroup effect estimates (OR, RR, HR, or SIR) with 95\% CI. The literature retrieval, review, and selection process are shown in Figure 1. The characteristics of cohort studies are shown in Table 1 . The quality assessment of observational studies was performed by NOS quality scale (Table 1). Quality assessment results suggested observational studies included had moderate or high quality, which might lead to heterogeneity and risk of bias.

\section{Meta-analysis results}

\section{Cancer risk after MI}

Four studies with 221,994 MI patients were included to estimate the incidence rate of cancer among patients with MI history. ${ }^{10,12,13,20}$ The pooled cancer incidence rate in MI patients was $9.5 \%$ (8.3\%-10.7\%, Figure 2$)$, which was comparable to that in non-MI controls $(11.1 \% ; 95 \% \mathrm{CI}=7.3 \%-14.8)$. Three studies reported the overall effect estimates in patients with MI. ${ }^{10,12,13}$ Pooled analyses of OR in the random-effects model showed that the increased cancer risk in patients with MI in comparison with controls had no statistical significance, and the heterogeneity among studies was high $(\mathrm{OR}=1.08$; $95 \% \mathrm{CI}=0.97-1.19, P=0.153 ; \mathrm{I}^{2}=90.8 \% ; P$ for heterogeneity $<0.01$; Figure 3).

\section{Subgroup analysis by gender}

Subgroup effect estimates based on gender were presented in four studies. ${ }^{10-13}$ Pooled analyses of OR in random-effects model demonstrated that the overall risk of cancer incidence in male patients with $\mathrm{MI}$ was nonsignificant $(\mathrm{OR}=1.04 ; 95 \%$ $\mathrm{CI}=0.99-1.10, P=0.124 ; \mathrm{I}^{2}=78.5 \% ; P$ for heterogeneity $<0.01$; Figure 4A). However, female patients with MI had a significantly increased risk of incident cancer $(\mathrm{OR}=1.10$; 95\% CI $=1.01-1.20, P=0.025 ; \mathrm{I}^{2}=82.9 \% ; P$ for heterogeneity $<0.01$; Figure 4B).

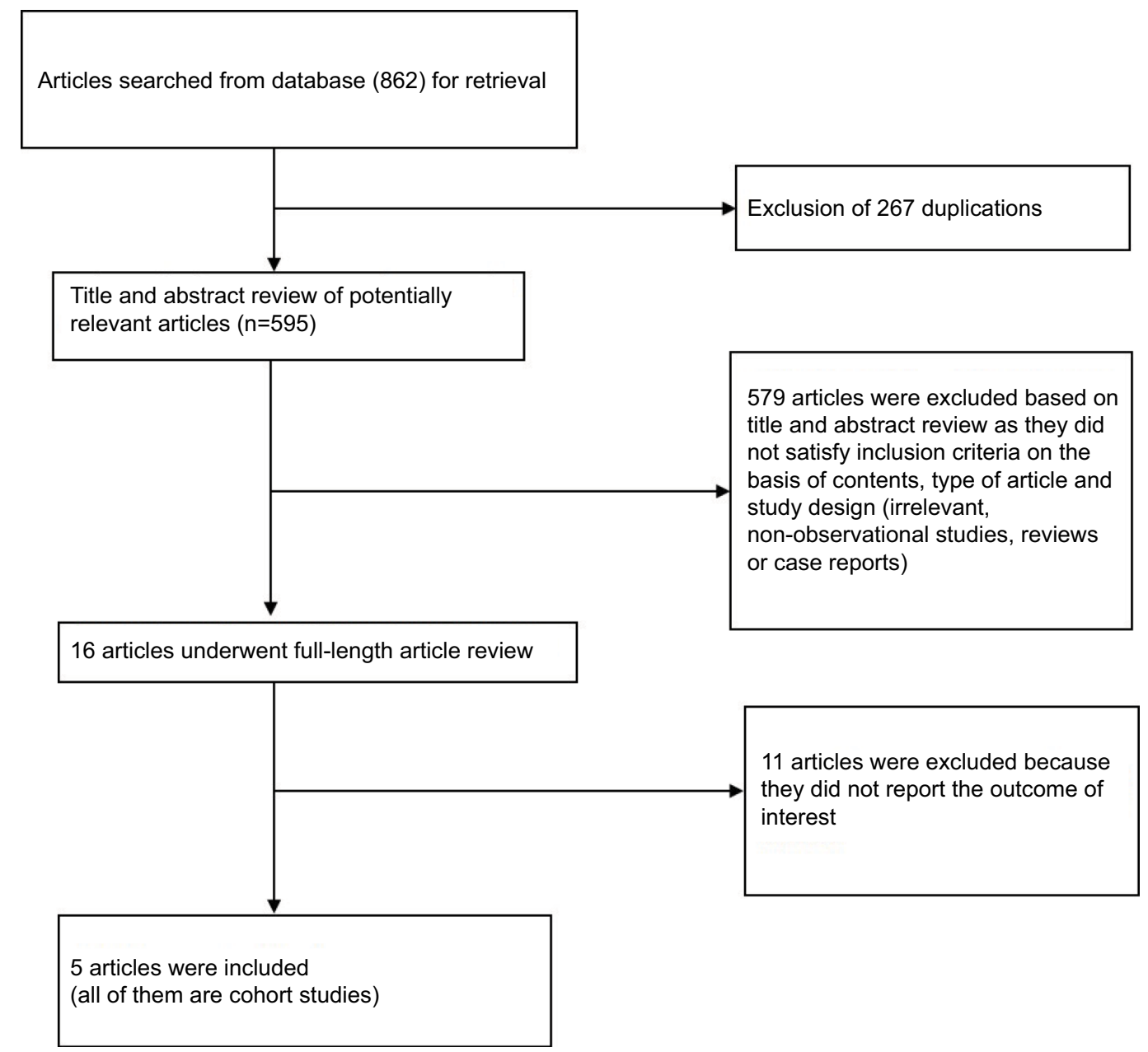

Figure I Flow diagram of literature review process. 
Table I Characteristics of studies included

\begin{tabular}{|c|c|c|c|c|c|c|c|c|c|c|}
\hline Study & Year & Country & Design & $\begin{array}{l}\text { No. } \\
\text { of MI } \\
\text { patients }\end{array}$ & $\begin{array}{l}\text { Age } \\
\text { (years) }\end{array}$ & $\begin{array}{l}\text { Male } \\
\text { proportion } \\
\text { (\%) }\end{array}$ & $\begin{array}{l}\text { OR or } \\
\text { equivalents } \\
\text { with } 95 \% \mathrm{CI}\end{array}$ & $\begin{array}{l}\text { Follow- } \\
\text { up time } \\
\text { (years) }\end{array}$ & $\begin{array}{l}\text { Adjusted } \\
\text { factors }\end{array}$ & $\begin{array}{l}\text { Quality } \\
\text { assessment }\end{array}$ \\
\hline $\begin{array}{l}\text { Hasin } \\
\text { et } \mathrm{al}^{20}\end{array}$ & 2016 & USA & Cohort & $|, 08|$ & $64 \pm 15$ & 60 & NA & $4.9 \pm 3.0$ & NA & Moderate \\
\hline $\begin{array}{l}\text { Pehrsson } \\
\text { et al"l }\end{array}$ & 2005 & Sweden & Cohort & NA & $<80$ & 65.20 & $\begin{array}{l}\text { Men: I.08 } \\
(I .04-I . I I) ; \\
\text { Women: I.I5 } \\
(I .09-I .2 I)\end{array}$ & $9.3(0-28)$ & Age & High \\
\hline $\begin{array}{l}\text { Dreyer } \\
\text { and } \\
\text { Olsen }^{10}\end{array}$ & 1998 & Denmark & Cohort & 96,891 & $\begin{array}{l}\text { Men: 63; } \\
\text { Women: } 69\end{array}$ & 67.97 & $\begin{array}{l}1.05 \\
(1.03-1.07)\end{array}$ & $5.9(1-17)$ & NA & Moderate \\
\hline $\begin{array}{l}\text { Rinde } \\
\text { et } \mathrm{al}^{12}\end{array}$ & 2017 & 更 & 更 & 更 & $62 \pm 13$ & 更 & $\begin{array}{l}\mathrm{I} .46 \\
(\mathrm{I} .2 \mathrm{I}-\mathrm{I} .77)\end{array}$ & $\begin{array}{l}\text { Median: } \\
15.7\end{array}$ & $\begin{array}{l}\text { Systolic blood } \\
\text { pressure, diabetes } \\
\text { mellitus, HDL, } \\
\text { smoking, physical } \\
\text { activity, and } \\
\text { education level }\end{array}$ & High \\
\hline $\begin{array}{l}\text { Malmborg } \\
\text { et } \mathrm{al}^{13}\end{array}$ & 2018 & Denmark & cohort & 122,275 & $\begin{array}{l}\text { Men: } 59.2 \\
(49.5-69.5) ; \\
\text { Women: } \\
68.5 \\
(58.1-76.0)\end{array}$ & 61.2 & $\begin{array}{l}0.97 \\
(0.92-1.01)\end{array}$ & $0-17$ & $\begin{array}{l}\text { Age, sex, } \\
\text { calendar year, } \\
\text { hypertension, } \\
\text { dyslipidemia, } \\
\text { diabetes, } \\
\text { COPD and } \\
\text { socioeconomic } \\
\text { status }\end{array}$ & High \\
\hline
\end{tabular}

Abbreviations: HDL, high-density lipoprotein; MI, myocardial infarction.

\begin{tabular}{|c|c|c|}
\hline Study & & $\%$ \\
\hline ID & ES $(95 \% \mathrm{Cl})$ & Weight \\
\hline Hasin 2016 & $0.09(0.07,0.11)$ & 18.27 \\
\hline Dreyer 1998 & $0.11(0.11,0.11)$ & 29.86 \\
\hline Rinde 2017 & $0.08(0.07,0.10)$ & 21.94 \\
\hline Malmborg 2018 & $0.09(0.09,0.09)$ & 29.94 \\
\hline Overall $\left(R^{2}=98.0 \%, P=0.000\right)$ & $0.10(0.08,0.11)$ & 100.00 \\
\hline Note: weights are from random effects analysis & & \\
\hline-0.11 & 0.11 & \\
\hline
\end{tabular}

Figure 2 Forest plot of cancer incidence rate after myocardial infarction. 


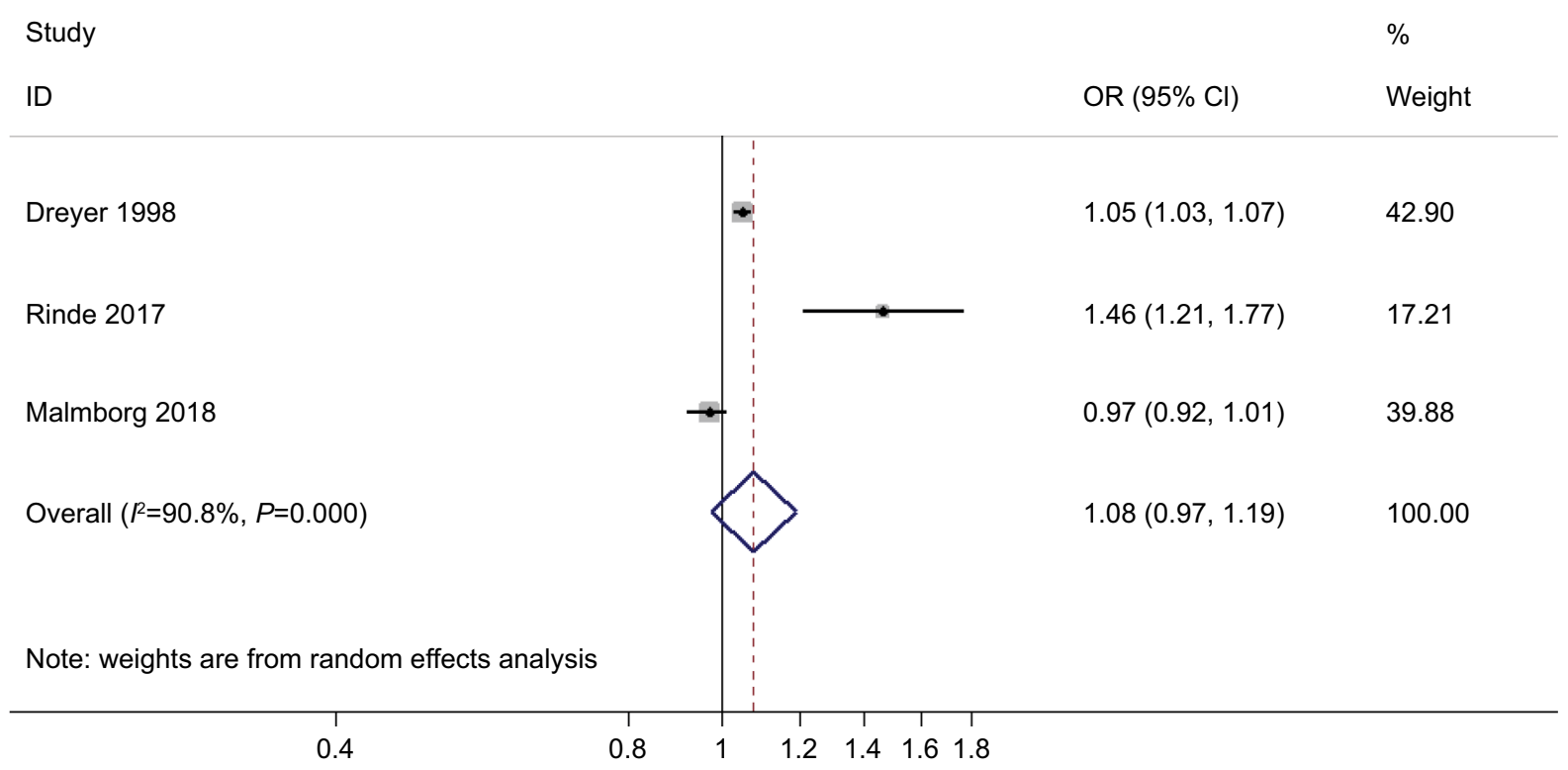

Figure 3 Forest plot of overall cancer risk after myocardial infarction.

\section{Subgroup analysis by cancer type}

Three studies reported the outcome of cancer types or sites. ${ }^{10,11,13}$ Although there was much difference in the classification of cancers in these studies, all of them provided the gender-stratified incidence of lung, prostate, and breast cancers. We found lung cancer risk was significantly increased both in male $(\mathrm{OR}=1.12 ; 95 \% \mathrm{CI}=1.05-1.19, P<0.01$; $\mathrm{I}^{2}=38.6 \% ; P$ for heterogeneity $=0.196$; Figure $\left.5 \mathrm{~A}\right)$ and female $\left(\mathrm{OR}=1.51 ; 95 \% \mathrm{CI}=1.15-1.99, P<0.01 ; \mathrm{I}^{2}=92.0 \%\right.$; $P$ for heterogeneity $<0.01$; Figure $5 \mathrm{~B}$ ) patients with $\mathrm{MI}$ history. However, the increased risk of sex-specific cancers including prostate cancer $(\mathrm{OR}=0.96 ; 95 \% \mathrm{CI}=0.85-1.09$, $P=0.546 ; \mathrm{I}^{2}=94.4 \%$; $P$ for heterogeneity $<0.01$; Figure $5 \mathrm{C}$ ) and breast cancer $(\mathrm{OR}=0.94 ; 95 \% \mathrm{CI}=0.86-1.04, P=0.222$; $\mathrm{I}^{2}=39.9 \% ; P$ for heterogeneity $=0.189$; Figure $5 \mathrm{D}$ ) had no statistical significance.

\section{Subgroup analysis by follow-up time}

Only two studies revealed the incidence of cancer in subjects with MI by time after the MI event. ${ }^{12,13}$ We observed the increased cancer risk was only significant in the first 6 months after MI with no heterogeneity (OR=1.93; 95\% $\mathrm{CI}=1.42-2.63, P<0.01 ; \mathrm{I}^{2}=0 \% ; P$ for heterogeneity $=0.606$; Figure 6A). After 6 months, the increased cancer risk vanished, which was reflected by the pooled ORs for 6 months to 1 -year $\left(\mathrm{OR}=1.03,95 \% \mathrm{CI}=0.92-1.15, P=0.627 ; \mathrm{I}^{2}=0 \% ; P\right.$ for heterogeneity $=0.786$; Figure $6 \mathrm{~B})$ and $>1$-year $(\mathrm{OR}=0.98$, 95\% CI $=0.93-1.04, P=0.585 ; \mathrm{I}^{2}=0 \% ; P$ for heterogeneity $=0.487$; Figure $6 \mathrm{C}$ ) follow-up after MI.

\section{Evaluation for publication bias}

Begg's and Egger's tests were performed to evaluate publication bias. For the overall cancer risk analysis of MI vs control, there was no significant publication bias (Begg's test, $P=0.602$; Egger's test, $P=0.816$ ).

\section{Discussion}

To our knowledge, this is the first systematic review and meta-analysis of published observational studies assessing the association between MI and incident cancer. Our results showed that the estimated cancer incidence rate after MI was $9.5 \%$ and the relation between $\mathrm{MI}$ and cancer incidence was uncertain. The pooled ORs of increased overall cancer risk were only significant in female patients, but not in male patients. Although the OR of cancer risk in female patients reached statistical significance, the absolute increased risk was only $10 \%(\mathrm{OR}=1.10 ; 95 \% \mathrm{CI}=1.01-1.20, P=0.025)$ and the heterogeneity was high. In terms of cancer type, the increased cancer risk was only significant for lung cancer, but not for prostate cancer or breast cancer. In addition, subgroup analysis by follow-up time suggested the increased risk of incident cancer did not persist over 6 months after MI event.

Sharing risk factors are one of the important reasons for association between MI and cancer. These shared risk factors can contribute to both the cardiovascular and the malignant event, with the malignancy occurring later. ${ }^{21} \mathrm{As}$ a result, chance is a possible explanation for the increased cancer incidence after MI, and the independent association 


\section{A}

Study $\quad \%$

ID $\quad$ OR $(95 \% \mathrm{Cl}) \quad$ Weight

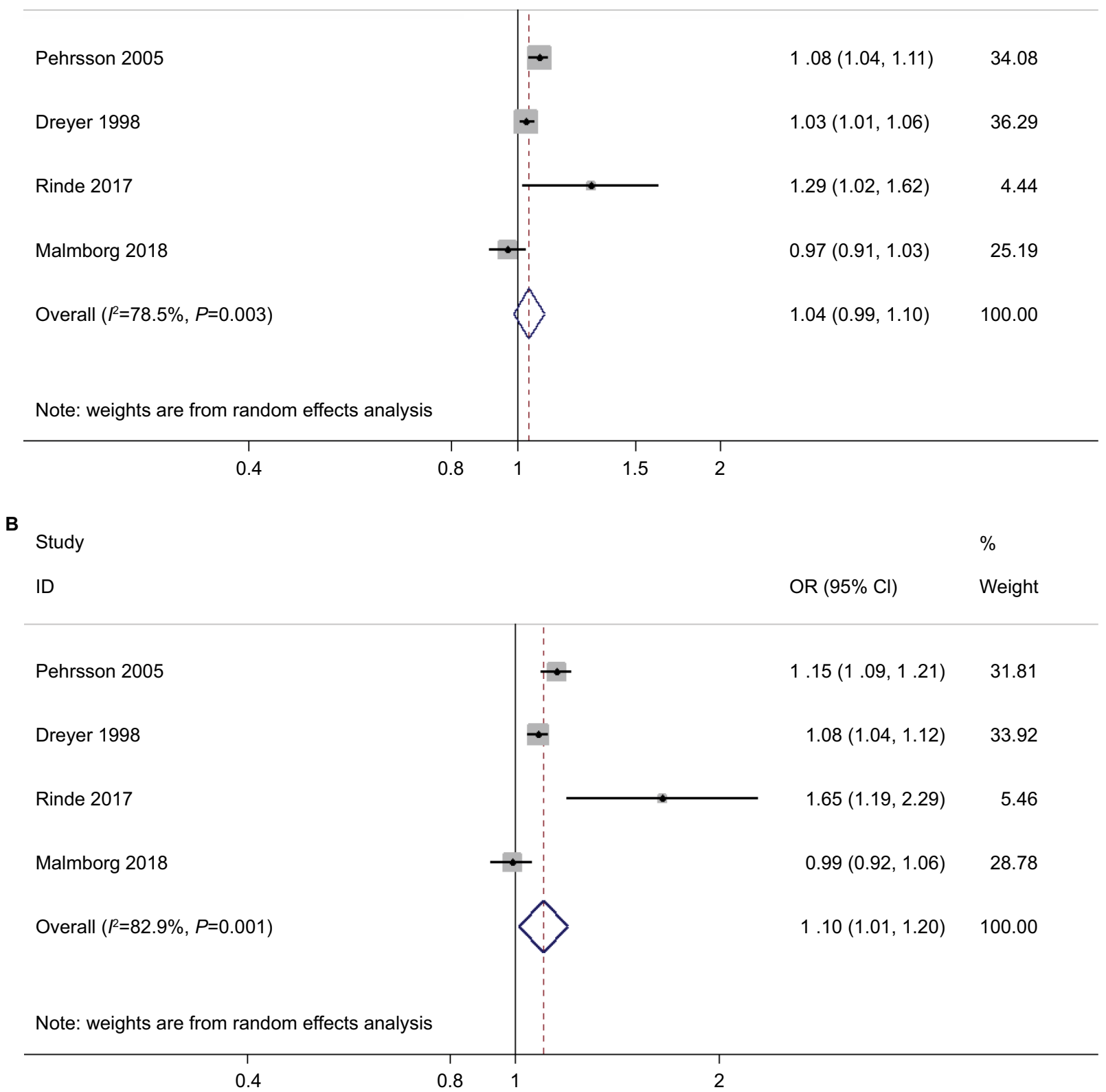

Figure 4 Forest plots of overall cancer risk after myocardial infarction by gender.

Note: (A) male patients; (B) female patients.

between MI and cancer may have been overlooked. Besides, the shared risk factor 'smoking', a known lung cancer cause, ${ }^{22}$ may partially account for our observation that lung cancer risk was significantly increased after MI.

In addition, the time since MI diagnosis must be considered when investigating cancer incidence. It is necessary to do such estimates by time, as cancer usually develops and evolves over several years. If cancer incidence is observed shortly after the start of MI follow-up, MI would be less likely to be a causal factor, and occult cancers could have occurred before the cardiovascular event. ${ }^{21}$ In our analysis, we did a subgroup analysis by follow-up time and found an interesting phenomenon. The risk of cancer incidence was the highest in the first follow-up period ( $<6$ months). With follow-up time increasing, the ORs decreased sharply and became nonsignificant. This suggested that the higher cancer 


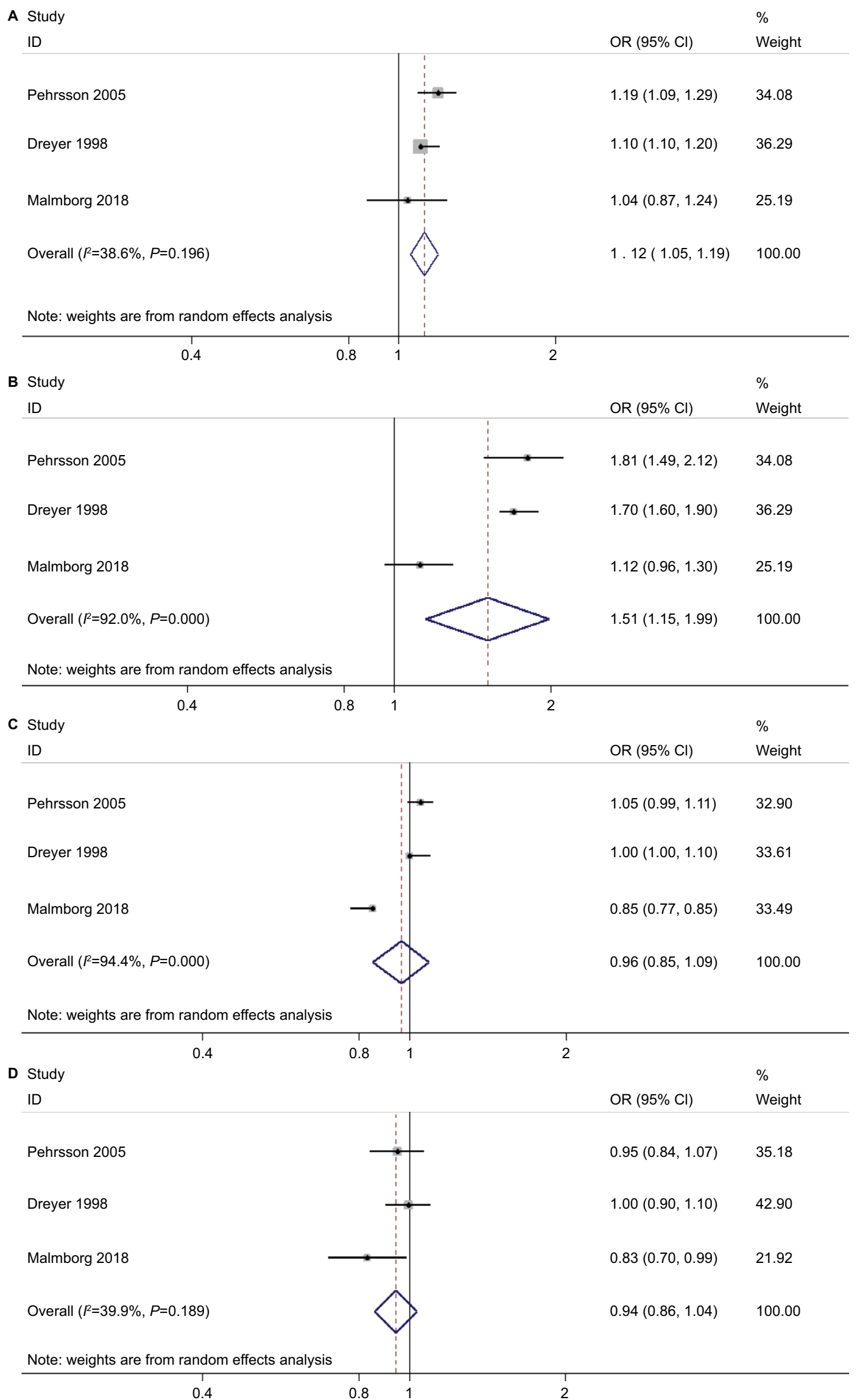

Figure 5 Forest plots of cancer risk after myocardial infarction by cancer types.

Note: (A) lung cancer in male patients; (B) lung cancer in female patients; (C) prostate cancer in male patients; (D) breast cancer in female patients. 
A Study

ID

OR $(95 \% \mathrm{Cl}) \quad$ Weight

Rinde 2017

Malmborg 2018

Overall $\left(R^{2}=98.0 \%, P=0.000\right)$

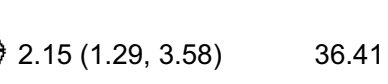

$1.82(1.23,2.67) \quad 63.59$

$1.93(1.42,2.63) \quad 100.00$

Note: weights are from random effects analysis

0.4

0.8

B Study

ID

C Study

ID

OR $(95 \% \mathrm{Cl}) \quad$ Weight

Rinde 2017

Malmborg 2018

Overall $(R=0.0 \%, P=0.487)$

Note: weights are from random effects analysis

0.4

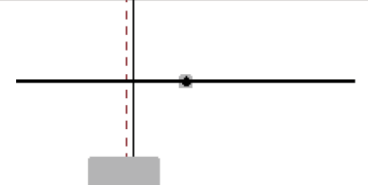

$1.13(0.76,1.68) \quad 2.33$

$0.98(0.92,1.04) \quad 97.67$

$0.98(0.93,1.04) \quad 100.00$

Figure 6 Forest plots of overall cancer risk after myocardial infarction by follow-up time.

Note: (A) $<6$ months; (B) 6 months-1 year; (C) $>1$ year. 
risk shortly after MI may not be due to MI itself, but other confounding factors such as surveillance bias. Patients with MI had more frequent clinical encounters with more diagnostic tests, especially in the first several months after MI event, and this would increase the chance of early detection of cancer. ${ }^{13}$

Although the above-mentioned shared risk factors, occult cancers, and surveillance bias may explain the increased cancer incidence after MI, we couldn't exclude the possibility that MI itself can cause a higher risk of long-term cancer development. A recent large cohort study presented that, after a median follow-up of 1,020 days, atherosclerotic cardiovascular disease (ASCVD) itself increased the risk of cancer incidence. ${ }^{23}$ On the other hand, a laboratory experimental study by Meijers et $\mathrm{al}^{24}$ just showed heart failure stimulates tumor growth by cardiac excreted circulating factors. MI belongs to ASCVD and can also lead to heart failure in some patients. Therefore, it is still possible that MI can have some effect on the long-term risk of cancer incidence. As Hasin et $\mathrm{al}^{21}$ summarized, malignancy may be caused by biological alterations or treatment modalities related to the cardiovascular diseases. In the future, the links between MI and new onset cancer remain to be established by more basic and clinical research.

\section{Limitations}

There are several limitations in our study. First, the present number of studies on MI and incident cancer is limited, especially in the investigation of cancers types (three studies) and cancer incidence by time (two studies). Since only two available studies were included in the analysis of cancer risk by follow-up time, the results should be interpreted with caution. Second, our study is related to the observational nature of the studies included with all inherited biases of observational designs. Third, heart failure also has some links with cancer incidence, but most of the studies included did not supply data on heart failure or left ventricular ejection fraction. Therefore, heart failure could become a confounder. However, current evidence represented the best available and all studies included were of moderate-to-high quality, including population-based studies.

\section{Conclusion}

From available evidence, the increased overall cancer risk after MI was only significant in female but not in male patients. Besides, the increased cancer risk could be driven by increased short-term cancer incidence after MI, and certain cancer types, such as lung cancer. However, due to the limitations listed above, further studies with larger sample sizes and long-term follow-up are warranted to establish the association between MI and new onset cancer.

\section{Acknowledgments}

This work was supported by a National Natural Science Foundation of China grant (81803939) to $\mathrm{Na} \mathrm{Li.}$

\section{Disclosure}

The authors report no conflicts of interest in this work.

\section{References}

1. Orozco-Beltran D, Cooper RS, Gil-Guillen V, et al. Trends in mortality from myocardial infarction. A comparative study between Spain and the United States: 1990-2006. Rev Esp Cardiol. 2012;65(12): 1079-1085.

2. Koene RJ, Prizment AE, Blaes A, Konety SH. Shared risk factors in cardiovascular disease and cancer. Circulation. 2016;133(11):1104-1114.

3. Johnson CB, Davis MK, Law A, Sulpher J. Shared risk factors for cardiovascular disease and cancer: implications for preventive health and clinical care in oncology patients. Can J Cardiol. 2016;32(7): 900-907.

4. Vidal-Vanaclocha F. Inflammation in the molecular pathogenesis of cancer and atherosclerosis. Reumatol Clin. 2009;5(Suppl 1):40-43.

5. Yusuf S, Hawken S, Ounpuu S, et al. Obesity and the risk of myocardial infarction in 27,000 participants from 52 countries: a case-control study. Lancet. 2005;366(9497):1640-1649.

6. Pischon T, Nimptsch K. Obesity and risk of cancer: an introductory overview. Recent Results Cancer Res. 2016;208:1-15.

7. Gu D, Kelly TN, Wu X, et al. Mortality attributable to smoking in China. N Engl J Med. 2009;360(2):150-159.

8. Spoon DB, Psaltis PJ, Singh M, et al. Trends in cause of death after percutaneous coronary intervention. Circulation. 2014;129(12): 1286-1294.

9. Pedersen F, Butrymovich V, Kelbæk H, et al. Short- and long-term cause of death in patients treated with primary PCI for STEMI. $J$ Am Coll Cardiol. 2014;64(20):2101-2108.

10. Dreyer L, Olsen JH. Cancer risk of patients discharged with acute myocardial infarct. Epidemiology. 1998;9(2):178-183.

11. Pehrsson SK, Linnersjö A, Hammar N. Cancer risk of patients with ischaemic syndromes. J Intern Med. 2005;258(2):124-132.

12. Rinde LB, Småbrekke B, Hald EM, et al. Myocardial infarction and future risk of cancer in the general population - the Tromsø study. Eur J Epidemiol. 2017;32(3):193-201.

13. Malmborg M, Christiansen CB, Schmiegelow MD, et al. Incidence of new onset cancer in patients with a myocardial infarction - a nationwide cohort study. BMC Cardiovasc Disord. 2018;18(1):198.

14. Stang A. Critical evaluation of the Newcastle-Ottawa scale for the assessment of the quality of nonrandomized studies in meta-analyses. Eur J Epidemiol. 2010;25(9):603-605.

15. Dersimonian R, Laird N. Meta-analysis in clinical trials. Control Clin Trials. 1986;7(3):177-188.

16. Hamling J, Lee P, Weitkunat R, Ambühl M. Facilitating meta-analyses by deriving relative effect and precision estimates for alternative comparisons from a set of estimates presented by exposure level or disease category. Stat Med. 2008;27(7):954-970.

17. Higgins JP, Thompson SG, Deeks JJ, Altman DG. Measuring inconsistency in meta-analyses. BMJ. 2003;327(7414):557-560.

18. Begg CB, Mazumdar M. Operating characteristics of a RANK correlation test for publication bias. Biometrics. 1994;50(4):1088-1101. 
19. Egger M, Smith GD. Bias in location and selection of studies. BMJ. 1998;316(7124):61-66.

20. Hasin T, Gerber Y, Weston SA, et al. Heart failure after myocardial infarction is associated with increased risk of cancer. $J$ Am Coll Cardiol. 2016;68(3):265-271.

21. Hasin T, Iakobishvili Z, Weisz G. Associated risk of malignancy in patients with cardiovascular disease: evidence and possible mechanism. Am J Med. 2017;130(7):780-785.
22. Lee PN, Forey BA, Coombs KJ. Systematic review with meta-analysis of the epidemiological evidence in the 1900 s relating smoking to lung cancer. BMC Cancer. 2012;12:385.

23. Suzuki M, Tomoike H, Sumiyoshi T, et al. Incidence of cancers in patients with atherosclerotic cardiovascular diseases. Int $J$ Cardiol Heart Vasc. 2017;17:11-16.

24. Meijers WC, Maglione M, Bakker SJL, et al. Heart failure stimulates tumor growth by circulating factors. Circulation. 2018;138(7):678-691.
Cancer Management and Research

\section{Publish your work in this journal}

Cancer Management and Research is an international, peer-reviewed open access journal focusing on cancer research and the optimal use of preventative and integrated treatment interventions to achieve improved outcomes, enhanced survival and quality of life for the cancer patient. The manuscript management system is completely online and includes
Dovepress

a very quick and fair peer-review system, which is all easy to use. Visit http://www.dovepress.com/testimonials.php to read real quotes from published authors. 